\title{
Related Subjects Dataset
}

National Cancer Institute

\section{Source}

National Cancer Institute. Related Subjects Dataset. NCI Thesaurus. Code C147183.

A dataset used to represent relationships between study subjects. (CDISC) 